\title{
Crescimento e acúmulo de cátions em plantas de moringa mantidas em solos salinos
}

\author{
Antonio Lucineudo Oliveira Freire ${ }^{1}$, José Romilson Paes de Miranda² \\ 1 Universidade Federal de Campina Grande, Centro de Saúde e Tecnologia Rural, Av. Universitária, s/n, CEP 58.708-110, Patos, PB, Brasil \\ ${ }^{2}$ Universidade Federal de Campina Grande, Centro de Desenvolvimento Sustentável do Semiárido, R. Luiz Grande, s/n, CEP 58.540-000, Sumé, PB, Brasil
}

*Autor correspondente:

lofreire@cstr.ufcg.edu.br

Termos para indexação:

Moringa oleifera

Estresse salino

Tolerância à salinidade

Index terms:

Moringa oleifera

Salt stress

Salt tolerance

Histórico do artigo:

Recebido em 24 ago 2011

Aprovado em 05 mar 2012

Publicado em 30 mar 2012

doi: 10.4336/2012.pfb.32.69.45

\begin{abstract}
Resumo - Com o objetivo de avaliar os efeitos da salinidade no crescimento e acúmulo de massa seca e cátions em plantas jovens de moringa (Moringa oleifera), testaram-se quatro tipos de solos, nas condutividades elétricas (C.E.) 0,49 (controle), 4,15, 6,33 e $10,45 \mathrm{dS} \mathrm{m}^{-1}$. O experimento foi conduzido em delineamento inteiramente casualizado, com quatro repetições. As plantas cresceram inicialmente em tubetes rígidos e, aos 30 dias após a emergência, foram transferidas para vasos contendo $10 \mathrm{~kg}$ de solo, de acordo com o tratamento de salinidade. A salinidade prejudica o crescimento inicial das plantas e acúmulo de cátions na parte aérea e nas raízes das plantas. Na fase inicial de crescimento, as plantas de moringa não inibem a absorção de $\mathrm{Na}$ e sua translocação para a parte aérea.
\end{abstract}

\section{Growth and cations accumulation in moringa plants cultivated in saline soils}

\begin{abstract}
The aim of this work was to evaluate the salinity effects on growth and dry matter and cations accumulation in moringa plants (Moringa oleifera). The experiment was conducted in completely randomized design, with four treatments, consisting of four soils (electrical conductivity (EC) 0.49 (control), 4.15, 6.33, $10.45 \mathrm{dS} \mathrm{m}^{-1}$ ) with four replications. Initially the plants were grown in rigid tubes, and 30 days after emergence, were transferred to pots containing $10 \mathrm{~kg}$ of soil, according to the salinity treatment. The parameters evaluated were plants height and dry matter and $\mathrm{N}, \mathrm{K}, \mathrm{Ca}, \mathrm{Mg}$ and $\mathrm{Na}$ accumulation in shoots and roots. The salinity is detrimental to initial plant growth and cation accumulation in shoots and roots plants. Young moringa plants were not effective in inhibiting the absorption of $\mathrm{Na}$ and its translocation to the shoot.
\end{abstract}

\section{Introdução}

As regiões áridas e semi-áridas ocupam cerca de $40 \%$ da superfície da Terra e apresentam problemas que limitam a produtividade das plantas, como períodos de seca prolongados, temperaturas altas e salinidade do solo, o qual tem aumentado em virtude do uso inadequado de técnicas agrícolas, como adubação excessiva e irrigação com água imprópria, transformando terras férteis e produtivas em terras áridas. Apenas no semiárido brasileiro, estima-se que a presença de solos salinos atinja cerca de nove milhões de hectares (Miranda et al., 2005).
A produtividade agrícola em várias partes do globo é afetada pela alta concentração de sais no solo, prejudiciais ao crescimento das plantas (Dardanelli et al., 2009). A grande concentração de sais no ambiente desencadeia vários tipos de estresses físicos e químicos nas plantas, promovendo respostas complexas que envolvem mudanças na morfologia, fisiologia e no metabolismo (Hasegawa et al., 2000; Musyimi et al., 2007).

Dentre os elementos que contribuem para a salinização dos solos, os principais são: $\mathrm{Ca}, \mathrm{Mg}, \mathrm{Na}, \mathrm{K}, \mathrm{Cl}$ e $\mathrm{S}$. 
Quando o teor de sódio é alto em relação aos demais cátions, este pode ser adsorvido pelo complexo de troca e, neste caso, as partículas de argila podem dispersar-se e o solo perde sua estrutura, tornando-se impermeável (Pizarro, 1978).

A moringa (Moringa oleifera) é uma arbórea de origem africana, com ampla utilização para fins não madeireiros, sendo empregada como medicinal e fonte de óleo (Katayon et al., 2006), além de ser utilizada no clareamento e tratamento de água (Sharma et al., 2006; Akhtar et al., 2007; Bhatti et al., 2007; Vieira et al., 2010). É uma espécie que apresenta tolerância ao estresse hídrico (Vieira et al., 2010) e, em relação à salinidade, tem se comportado como uma planta halofílica (Miranda et al., 2005). Algumas pesquisas têm demonstrado redução no crescimento e acúmulo de nutrientes de plantas de moringa em função da salinidade (Miranda et al., 2002, 2005). No entanto, esses trabalhos foram conduzidos em solução nutritiva, empregando o $\mathrm{NaCl}$, existindo a necessidade de se verificar o seu comportamento em solos salinos, uma vez que vários outros sais presentes nesses solos contribuem para a sua salinização.

Dessa forma, desenvolveu-se esse trabalho com o objetivo de avaliar o crescimento e o acúmulo de cátions em plantas crescendo em solos salinos, durante a fase inicial de crescimento.

\section{Material e métodos}

O experimento foi conduzido em ambiente telado, no viveiro florestal pertencente à Unidade Acadêmica de Engenharia Florestal da Universidade Federal de
Campina Grande, Campus de Patos, PB, localizada nas coordenadas geodésicas $7^{\circ} 03^{\prime} 34^{\prime \prime} \mathrm{S}$ e $37^{\circ} 16^{\prime} 19^{\prime \prime} \mathrm{O}$, altitude de $250 \mathrm{~m}$.

O delineamento experimental utilizado foi inteiramente casualizado, com quatro tratamentos, que corresponderam a solos com salinidades diferentes, expressas como condutividade elétrica (CE) 0,49 (controle); 4,15; 6,33 e 10,45 $\mathrm{dS} \mathrm{m}^{-1}$, e quatro repetições por tratamento.

As sementes de moringa, provenientes de árvores matrizes crescendo no viveiro florestal da Universidade Federal de Campina Grande, em Patos, PB, foram germinadas em tubetes de $250 \mathrm{~cm}^{3}$, contendo uma mistura de subsolo + matéria orgânica (esterco bovino) (2:1). Aos 30 dias após a emergência (DAE), plantas uniformes quanto à altura foram transferidas individualmente para vasos contendo $10 \mathrm{~kg}$ de substrato.

Para a composição deste substrato foram utilizados solos de diferentes origens e matéria orgânica $(2: 1)$. Os solos foram coletados na profundidade de $0-20 \mathrm{~cm}$ e submetidos a análises químicas (Tabela 1) e, com exceção do solo não salino, os demais foram coletados em áreas de perímetros irrigados.

Os vasos foram irrigados diariamente com água de torneira (C.E. $0,06 \mathrm{dS} \mathrm{m}^{-1}$ ), de maneira a atingir $60 \%$ da capacidade do vaso, através de pesagem. Aos $90 \mathrm{DAE}$ (60 dias após a transferência para a condição salina), avaliou-se a altura das plantas. Em seguida, as plantas foram cortadas e separadas em parte aérea e raízes, acondicionadas em sacos de papel e transferidas para estufa a $70{ }^{\circ} \mathrm{C}$, até obtenção da massa constante. Após a secagem, esses componentes foram submetidos à pesagem, para a determinação da massa seca, e moídos

Tabela 1. Características químicas dos solos estudados.

\begin{tabular}{|c|c|c|c|c|c|c|c|c|c|c|c|}
\hline \multirow[t]{2}{*}{ Solo } & $\mathbf{C E}$ & pH & $\mathbf{P}$ & $\mathbf{C a}$ & Mg & $\mathbf{K}$ & $\mathbf{N a}$ & $\mathbf{H}+\mathbf{A l}$ & $\mathbf{T}^{*}$ & $\mathbf{V}^{*}$ & $\mathbf{S B}^{*}$ \\
\hline & $d S m^{-1}$ & $\mathrm{CaCl}_{2}$ & $\mathrm{mg} \mathrm{cm}^{-3}$ & ----- & ----- & emol & $1 m^{-3}---$ & & ------- & -\%-- & - \\
\hline $\begin{array}{c}\text { Neossolo } \\
\text { litólico }^{1}\end{array}$ & 0,49 & 7,6 & 149,4 & 10,2 & 3,2 & 1,2 & 0,8 & 0,9 & 16,3 & 94 & 15,4 \\
\hline $\begin{array}{l}\text { Neossolo } \\
\text { flúvico }^{2}\end{array}$ & 4,15 & 7,4 & 140,0 & 5,2 & 1,0 & 1,2 & 26,4 & 0,5 & 34,32 & 99 & 33,82 \\
\hline $\begin{array}{l}\text { Neossolo } \\
\text { flúvico }^{3}\end{array}$ & 6,33 & 7,7 & 142,5 & 18,1 & 3,0 & 1,2 & 19,5 & 0,9 & 42,72 & 98 & 41,82 \\
\hline $\begin{array}{l}\text { Neossolo } \\
\text { flúvico }{ }^{3}\end{array}$ & 10,45 & 7,7 & 147,0 & 4,0 & 1,9 & 1,2 & 26,0 & 0,8 & 33,9 & 98 & 33,1 \\
\hline
\end{tabular}

${ }^{1}$ Coletado no município de Patos-PB; ${ }^{2}$ Coletado no Perímetro Irrigado de São Gonçalo (Sousa-PB); ${ }^{3}$ Coletado no perímetro irrigado de Capoeira (São José do Bomfim-PB). 
para a quantificação dos teores de nitrogênio, potássio, cálcio, magnésio e sódio.

No extrato obtido por digestão nítrico-perclórica foram determinados os teores de $\mathrm{Ca}$ e $\mathrm{Mg}$, por espectrofotometria de absorção atômica, e K e Na por fotometria de chama de emissão (Malavolta et al., 1997). Os teores de nitrogênio total $(\mathrm{N})$ foram determinados pelo método semimicro Kjeldahl, sendo a destilação e a titulação realizadas segundo Bremner \& Edwards (1965). A partir destes teores, determinou-se o acúmulo dos nutrientes com base na massa seca.

Os dados foram submetidos à análise de variância e as médias comparadas pelo teste de Tukey $(\mathrm{P} \leq 0,05)$.

\section{Resultados e discussão}

Analisando-se a Figura 1, observa-se aumento nos acúmulos de Na com a elevação da salinidade do solo, tanto nas raízes quanto na parte aérea das plantas. $\mathrm{O}$ valor de $\mathrm{Na}$ acumulado nas raízes das plantas crescidas em solos com CE 4,15, 6,33 e 10,45 $\mathrm{dS} \mathrm{m}^{-1}$ foram, respectivamente, 7,9, 12 e 19,8 vezes maior do que o das plantas em solo não salino. Na parte aérea, esses valores foram, respetivamente, iguais a 62,6, 101,4 e 172 vezes maior.

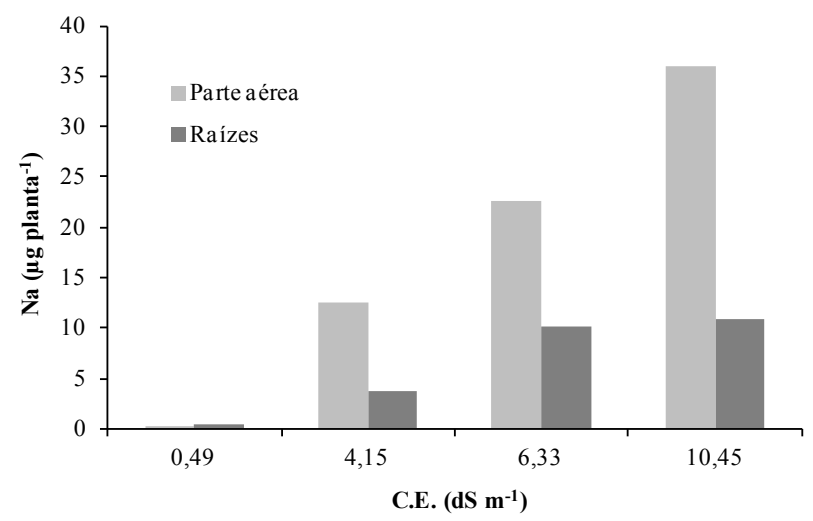

Figura 1. Acúmulo de $\mathrm{Na}$ em plantas de moringa mantidas em solos com diferentes níveis de salinidade.

À proporção que o nível de salinidade aumentou, houve redução na altura (Figura 2A) e no acúmulo de massa seca das plantas (Figura 2B). Quando as plantas foram submetidas ao nível mais baixo de salinidade $\left(4,15 \mathrm{dS} \mathrm{m}^{-1}\right)$, houve redução de apenas $14 \%$ na altura das plantas, enquanto que, no nível mais elevado $\left(10,45 \mathrm{dS} \mathrm{m}^{-1}\right)$, essa redução chegou a $36 \%$, quando comparadas às plantas do tratamento controle. Inibição no alongamento da parte aérea em função da salinidade é resultado da combinação do aumento na relação $\mathrm{Na} /$ $\mathrm{Ca}$ no apoplasto foliaar com o suprimento inadequado de água (Rengel, 1992).
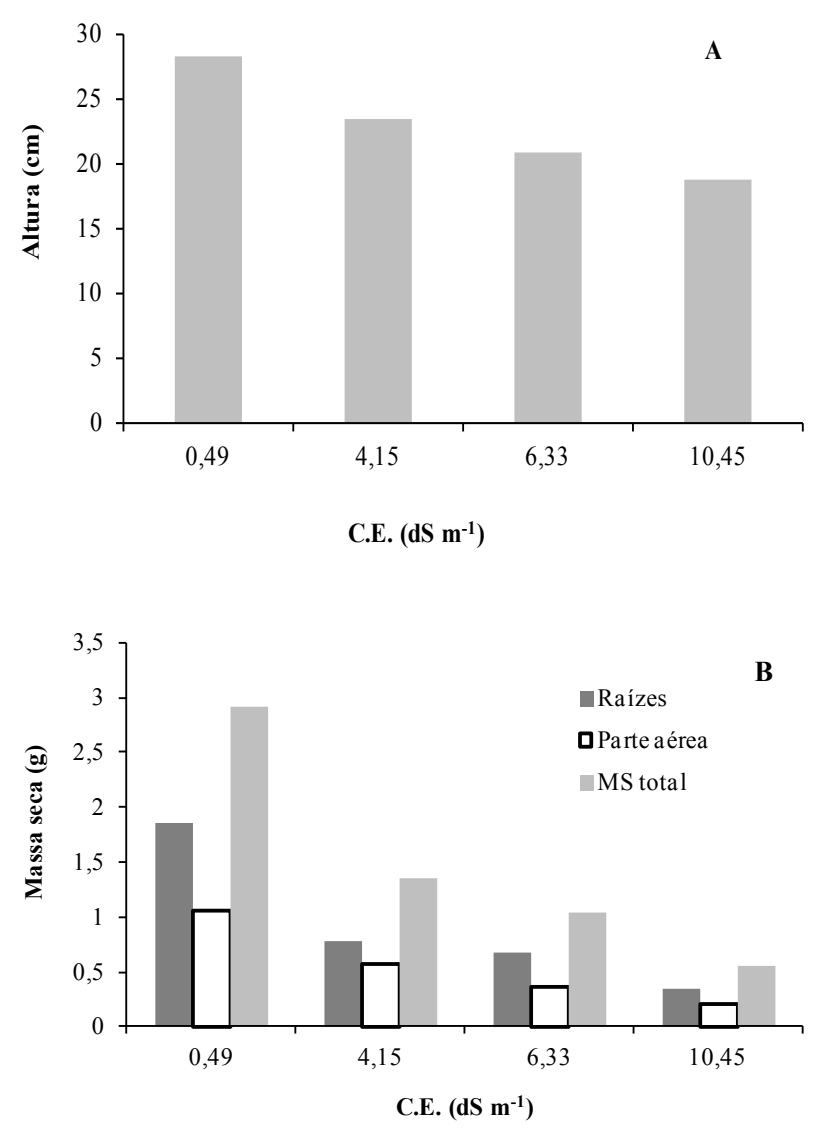

Figura 2. Altura (A) e massa seca (B) de plantas de moringa mantidas em solos com diferentes níveis de salinidade.

Em relação ao acúmulo de massa seca (Figura 2B), os efeitos da salinidade foram mais intensos na parte aérea (redução de $86 \%$ ) do que nas raízes (redução de $74 \%$ ), quando se compara as plantas do tratamento controle com o mais alto nível de salinidade. Mesmo no nível mais baixo de salinidade $\left(4,15 \mathrm{dS} \mathrm{m}^{-1}\right)$, essas reduções foram consideradas elevadas, chegando a $34 \%$, 29\% e $31 \%$, respectivamente, nas massas secas da parte aérea, das raízes e massa seca total. Esses resultados evidenciam a sensibilidade dessas plantas à condição de salinidade do solo. Em plantas de Pinus taeda, Maeda et al. (2010) observaram que, dentre os parâmetros de crescimento analisados, a biomassa seca de raízes foi a mais afetada pela salinidade, e que, assim como a biomassa seca total, houve tendência de redução 
a partir de $0,55 \mathrm{dS} \mathrm{m}^{-1}$ de condutividade elétrica. Vários outros estudos têm demonstrado redução no crescimento e na produção de biomassa das plantas causados pela salinidade do meio (Lacerda et al., 2001; Miranda et al., 2002, 2005; Neves et al., 2004), os quais podem ser devido aos efeitos osmóticos, tornando a água cada vez menos disponível para as plantas, além dos efeitos nutricionais e tóxicos (Munns, 2002). Além disso, há interferência no metabolismo dos açúcares, reduzindo o crescimento e a produção das plantas (Serrato Valenti et al., 1991). Não apenas a área foliar diminui em função da salinidade, mas também a fixação líquida do $\mathrm{CO}_{2}$ por unidade de área foliar, enquanto que a respiração aumenta, promovendo redução drástica na assimilação líquida de $\mathrm{CO}_{2}$ por unidade de área foliar por dia.

$\mathrm{O}$ acúmulo de $\mathrm{N}$ reduziu com o aumento na salinidade (Figura 3A). As plantas submetidas aos tratamentos CE 4,15 e 10,45 $\mathrm{dS} \mathrm{m}^{-1}$ apresentaram, respectivamente, valor de $\mathrm{N}$ na parte aérea cerca de 1,6 e 25 vezes inferior ao das plantas do tratamento controle. Entretanto, nas raízes, os mesmos tratamentos apresentaram teores em torno de 1,6 e 2,4 vezes menores. Percebe-se, então, que a salinidade reduziu a translocação de $\mathrm{N}$ para a parte aérea das plantas, possivelmente devido ao déficit hídrico que a salinidade causa, reduzindo a absorção de água e sua posterior translocação para os ramos e folhas (Tabela 2).

Redução na absorção de nutrientes em função da alta salinidade tem sido observada por outros autores, tanto em moringa como em outras plantas. Miranda et al. (2002) verificaram que o teor de $\mathrm{N}$ em plantas de moringa aumentou até o nível de salinidade de $37 \mathrm{mmol} \mathrm{L}^{-1}$ de $\mathrm{NaCl}$, reduzindo com o aumento da quantidade do sal na solução nutritiva. Em plantas de cajueiro, Miranda et al. (2004) verificaram comportamento quadrático, com decréscimo nos teores foliares de $\mathrm{N}$, atingindo valor mínimo de $\mathrm{N}$ nas folhas a $97,3 \mathrm{mmol} \mathrm{L}^{-1}$ de $\mathrm{NaCl}$. Essas reduções nos teores de $\mathrm{N}$ nas plantas em função da salinidade podem ser devido à inibição na absorção de $\mathrm{NO}_{3}^{-}$(Botella et al., 1997).

Foi verificada redução no acúmulo de $\mathrm{K}$, tanto na parte aérea como nas raízes, à medida que a salinidade do solo aumentava (Figura 3B). Concordando com esses resultados, Neves et al. (2004), Fernandes et al. (2002), Lacerda et al. (2001) e Viana et al. (2001) observaram redução nos teores de $\mathrm{K}$ com o aumento da salinidade. De acordo com a Tabela 2, verifica-se que houve redução na razão concentração de $\mathrm{K}$ da parte aérea/raízes, quando as plantas foram submetidas ao nível mais elevado de salinidade. A redução no acúmulo de $\mathrm{K}$ em razão da salinidade é prejudicial ao crescimento das plantas e produção de massa seca, uma vez que esse íon tem papel primordial no ajustamento osmótico e na manutenção da turgescência celular, além da sua importância no mecanismo estomático, e consequentemente, nas relações hídricas do vegetal. O efeito antagônico do Na sobre o K é um processo já conhecido, sugerindo competição entre esses dois íons pelos sítios de absorção na membrana plasmática (Hasegawa et al., 2000) ou, como sugeriu Rengel (1992), a salinidade causa aumento no efluxo de $\mathrm{K}$ das raízes para o meio de crescimento em virtude de distúrbios na integridade das membranas.

Em relação ao acúmulo de $\mathrm{Ca}$, houve redução com o aumento da salinidade, sendo que o efeito foi mais intenso nas raízes (Figura 3C). Percebe-se que as plantas do tratamento controle apresentavam mais $\mathrm{Ca}$ nas raízes do que na parte aérea e que, com o aumento da salinidade, esse comportamento foi se invertendo, aproximando-se da igualdade (Tabela 2). Segundo Lynch \& Läuchli (1985) além de inibir o movimento desse nutriente da raiz para a parte aérea, $\mathrm{o} \mathrm{NaCl}$ pode reduzir sua disponibilidade na solução, causando precipitação e formação de pares iônicos. Cachorro et al. (1994) afirmaram que concentrações elevadas de $\mathrm{Na}$ no meio externo podem reduzir a atividade do Ca na solução, promovendo decréscimo na quantidade disponível desse cátion e, consequentemente, na absorção pelas raízes. Concordando com os resultados obtidos, Viana et al. (2001), Miranda et al. (2002) e Fernandes et al. (2002) verificaram redução nos teores de Ca com a elevação da salinidade no meio de crescimento.

Comportamento semelhante foi observado em relação ao acúmulo de $\mathrm{Mg}$, que foi reduzindo com o aumento da salinidade (Figura 3D), e a concentração desse cátion na parte aérea era sempre superior à observada nas raízes (Tabela 2). Fernandes et al. (2002), Miranda et al. (2002) e Costa et al. (2008) observaram redução drástica nos teores foliares de $\mathrm{Mg}$ com elevação da concentração de $\mathrm{NaCl}$ na solução nutritiva. Essa redução na concentração de $\mathrm{Mg}$ causada pela salinidade pode ser resultado, segundo Hu \& Schmidhalter (1997), da competição iônica existente entre o mesmo e o Na nos sítios de absorção das raízes. Deficiência de magnésio causada pela salinidade pode reduzir o crescimento das plantas, em virtude de reduções na taxa fotossintética.

Analisando-se a Tabela 3, nota-se que a elevação na salinidade foi acompanhada por aumento linear nas 

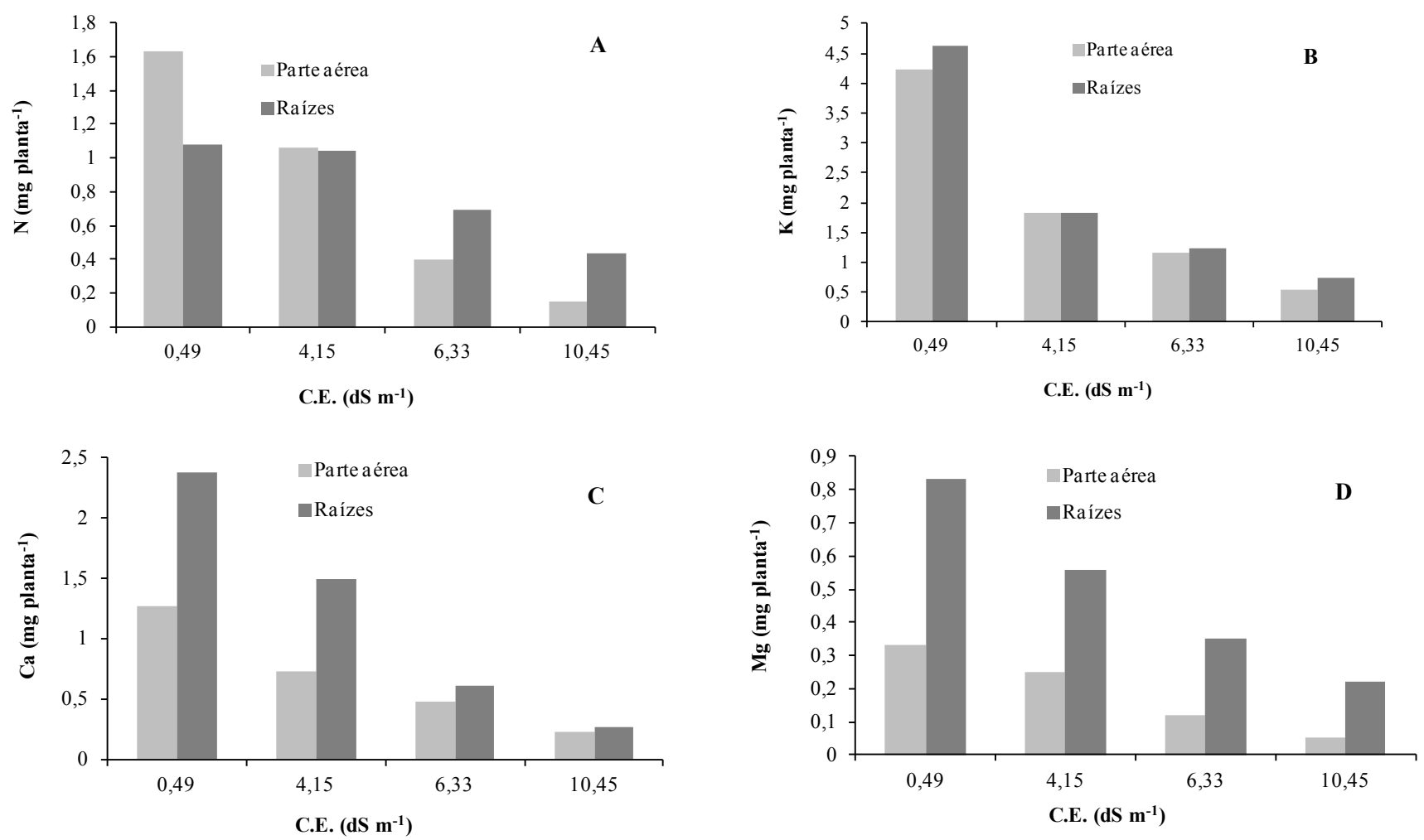

Figura 3. Acúmulo de $\mathrm{N}(\mathrm{A}), \mathrm{K}(\mathrm{B}), \mathrm{Ca}(\mathrm{C})$ e $\mathrm{Mg}(\mathrm{D})$ em plantas de moringa mantidas em solos com diferentes níveis de salinidade.

Tabela 2. Razão da concentração de nutrientes na parte aérea pela concentração de nutrientes nas raízes, de plantas de moringa em função da salinidade do solo.

\begin{tabular}{cccccc}
\hline $\begin{array}{c}\text { Condutividade } \\
\text { elétrica }\left(\mathbf{d} \mathbf{S ~ m}^{-1}\right)\end{array}$ & $\mathbf{N}$ & $\mathbf{K}$ & $\mathbf{C a}$ & $\mathbf{M g}$ & $\mathbf{N a}$ \\
\hline 0,49 & $1,51 \mathrm{a}$ & $0,92 \mathrm{a}$ & $0,53 \mathrm{~b}$ & $0,40 \mathrm{a}$ & $0,34 \mathrm{c}$ \\
4,15 & $1,02 \mathrm{~b}$ & $0,99 \mathrm{a}$ & $0,49 \mathrm{~b}$ & $0,45 \mathrm{a}$ & $3,32 \mathrm{a}$ \\
6,33 & $0,58 \mathrm{c}$ & $0,94 \mathrm{a}$ & $0,77 \mathrm{a}$ & $0,34 \mathrm{~b}$ & $2,22 \mathrm{~b}$ \\
10,45 & $0,34 \mathrm{c}$ & $0,74 \mathrm{~b}$ & $0,81 \mathrm{a}$ & $0,23 \mathrm{c}$ & $3,30 \mathrm{a}$ \\
\hline
\end{tabular}

Médias seguidas de letras iguais nas colunas não diferem estatisticamente entre si pelo teste de Tukey $(\mathrm{P} \leq 0,05)$.

Tabela 3. Razão entre os cátions, nas raízes e na parte aérea, de plantas de moringa em função da salinidade do solo.

\begin{tabular}{|c|c|c|c|c|c|c|}
\hline \multirow{2}{*}{$\begin{array}{l}\text { Condutividade } \\
\text { elétrica }\left(\mathrm{dS} \mathrm{m}^{-1}\right)\end{array}$} & \multicolumn{3}{|c|}{ Raízes } & \multicolumn{3}{|c|}{ Parte aérea } \\
\hline & $\mathrm{Na} / \mathrm{K}$ & $\mathrm{Na} / \mathrm{Ca}$ & $\mathrm{Na} / \mathrm{Mg}$ & $\mathrm{Na} / \mathrm{K}$ & $\mathrm{Na} / \mathrm{Ca}$ & $\mathrm{Na} / \mathrm{Mg}$ \\
\hline 0,49 & $0,08 \mathrm{~d}$ & $0,15 \mathrm{~d}$ & $0,42 \mathrm{~d}$ & $0,03 \mathrm{~d}$ & $0,09 \mathrm{~d}$ & $0,36 \mathrm{~d}$ \\
\hline 4,15 & $2,07 \mathrm{c}$ & $2,55 \mathrm{c}$ & $6,79 \mathrm{c}$ & $6,92 \mathrm{c}$ & $17,26 \mathrm{c}$ & $50,40 \mathrm{c}$ \\
\hline 6,33 & $8,23 \mathrm{~b}$ & $16,72 \mathrm{~b}$ & $29,14 \mathrm{~b}$ & $19,48 \mathrm{~b}$ & $48,09 \mathrm{~b}$ & $188,33 \mathrm{~b}$ \\
\hline 10,45 & $14,93 \mathrm{a}$ & $40,37 \mathrm{a}$ & $49,55 \mathrm{a}$ & $66,67 \mathrm{a}$ & $163,04 \mathrm{a}$ & $720,00 \mathrm{a}$ \\
\hline
\end{tabular}

Médias seguidas de letras iguais nas colunas não diferem estatisticamente entre si pelo teste de Tukey $(\mathrm{P} \leq 0,05)$. 
relações entre $\mathrm{Na}$ e os demais cátions analisados, sendo que os maiores valores foram verificados na parte aérea. Resultados semelhantes foram verificados por Fernandes et al. (2002). Não ocorreu, portanto, seletividade por parte da membrana plasmática, possibilitando a absorção do $\mathrm{Na}$, promovendo redução na absorção dos cátions (Figura 3) e, consequentemente, no crescimento e na fitomassa das plantas (Figura 1).

Várias pesquisas têm mostrado o aumento da relação $\mathrm{Na} / \mathrm{K}, \mathrm{Na} / \mathrm{Ca}$ e $\mathrm{Na} / \mathrm{Mg}$ em função da salinidade (Azevedo Neto \& Tabosa, 2000; Fernandes et al., 2002; Garcia et al., 2007). A manutenção de baixas relações $\mathrm{Na} / \mathrm{K}, \mathrm{Na} / \mathrm{Ca}$ e $\mathrm{Na} / \mathrm{Mg}$ é um importante critério para caracterizar a tolerância das plantas à salinidade (Saur et al., 1995). Quando a relação $\mathrm{Na} / \mathrm{Ca}$ é alta, o $\mathrm{Na}$ promove o deslocamento do $\mathrm{Ca}$ da membrana celular, acarretando em perda da sua integridade e consequente desequilíbrio na absorção dos íons (Marschner, 2000). Para o bom funcionamento das células sob condições salinas é necessária a manutenção de relações adequadas de $\mathrm{Na} / \mathrm{K}$ nos tecidos (Greenway \& Munns, 1980). Ainda segundo esses autores, a relação $\mathrm{Na} / \mathrm{K}$ pode ser utilizada como índice indicador da toxicidade de $\mathrm{Na}$, uma vez que esse íon inibe a atividade das enzimas que necessitam de K como cofator.

\section{Conclusões}

$\mathrm{Na}$ fase inicial de crescimento, as plantas de moringa não inibem a absorção de $\mathrm{Na}$ e sua translocação para a parte aérea.

A salinidade prejudica o acúmulo de cátions na parte aérea e nas raízes e o crescimento inicial das plantas.

\section{Referências}

AKHTAR, M.; HASANY, S. M.; BHANGER, M. I.; IQBAL, S. Sorption potential of Moringa oleifera pods for the removal of organic pollutants from aqueous solutions. Journal of Hazardous Materials, Amsterdam, v. 141, n. 3, p. 546-556, 2007.

AZEVEDO NETO, A. D.; TABOSA, J. N. Estresse salino em plântulas de milho. Parte II: distribuição dos macronutrientes catiônicos e suas relações com o sódio. Revista Brasileira de Engenharia Agrícola e Ambiental, Campina Grande, v. 4, n. 2, p. 165-171, 2000.
BHATTI, H. N.; MUMTAZ, B.; HANIF, M. A.; NADEEM, R. Removal of Zn (II) ions from aqueous solution using Moringa oleifera Lam. (horseradish tree) biomass. Process Biochemistry, London, v. 42, p. 547-553, 2007.

BOTELLA, M. A.; MARTINEZ, V.; NIEVES, M.; CERDA, A. Effect of salinity on the growth and nitrogen uptake by wheat seedlings. Journal of Plant Nutrition, New York, v. 20, p. 793-804, 1997.

BREMNER, M.; EDWARDS, A. P. Determination and isotope ratio analysis of different forms of nitrogen in soils. I. Apparatus and procedures for distillation and determination for ammonium. Soil Science Society American Proceedings, v. 29, p. 504-507, 1965.

CACHORRO, P.; ORTIZ, A.; CERDÁ, A. Implications of calcium nutrition on the response of Phaseolus vulgaris L. to salinity. Plant and Soil, Dordrecht, v. 159, n. 2, p. 205-212, 1994.

COSTA, D. M. A.; MELO, H. N. S.; FERREIRA, S. R.; SANTAS, J.

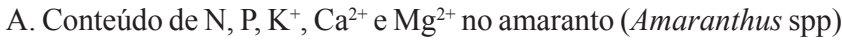
sob estresse salino e cobertura morta. Revista Ciência Agronômica, Fortaleza, v. 39, n. 2, p. 209-216, 2008.

DARDANELLI, M. S.; GONZÁLES, P. S.; MEDEOT, D. B.; PAULUCCI, N. S.; BUENO, M. A.; GARCIA, M. B. Effects of peanut rhizobia on the growth and symbiotic performance of Arachis hypogaea under abiotic stress. Symbiosis, Philadelphia, v. 47, p. 175-180, 2009

FERNANDES, A. R.; CARVALHO, J. G.; CURI, N.; PINTO, J. E. B. P.; GUIMARÃES, P. T. G. Nutrição mineral de mudas de pupunheira sob diferentes níveis de salinidade. Pesquisa Agropecuária Brasileira, Brasília, DF, v. 37, n. 11, p. 1613-1619, 2002.

GARCIA, G. O.; FERREIRA, P. A.; MIRANDA, G. V.; NEVES, J. C. L.; MORAES, W. B.; SANTOS, D. B. Teores foliares dos macronutrientes catiônicos e suas relações com o sódio em plantas de milho sob estresse salino. Idesia, Chile, v, 25, n. 3, p. 93-106, 2007.

GREENWAY, H.; MUNNS, R. Mechanisms of salt tolerance in nonhalophytes. Annual Review of Plant Physiology, Madison, v. 31, p. 149-190, 1980.

HASEGAWA, P. M.; BRESSAN, R. A.; ZHU, J.; BOHNERT, H. J. Plant cellular and molecular responses to high salinity. Annual Review of Plant Physiology and Molecular Biology, Palo Alto, v. 51, p. 463-499, 2000.

HU, Y.; SCHMIDHALTER, U. Interactive effects of salinity and macronutrient level on wheat: part II: composition. Journal do Plant Nutrition, New York, v. 20, n. 9, p. 1169-1182, 1997.

KATAYON, S.; NOOR, M. J.; ASMA, M.; GHANI, L. A.; THAMER, A. M.; AZNI, I.; AHMAD, J.; KHOR, B. C.; SULEYMAN, A. M. Effects of storage conditions of Moringa oleifera seeds on its performance in coagulation. Resource Technology, v. 97, n. 13, p. 1455-1460, 2006.

LACERDA, C. F.; CAMBRAIA, J.; CANO, M. A. O.; RUIZ, H. A. Plant growth and solute accumulation and distribution in two sorghum genotypes, under $\mathrm{NaCl}$ stress. Revista Brasileira de Fisiologia Vegetal, Londrina, v. 13, n. 3, p. 270-284, 2001. 
LYNCH, J.; LÄUCHLI, A. Salt stress disturbs the calcium nutrition of barley (Hordeum vulgare). New Phytologist, Cambridge, v. 99, n. 3, p. 345-354, 1985.

MAEDA, S.; SILVA, H. D.; BELLOTE, A. F. J. Efeito da salinidade em características biométricas e na nutrição de Pinus taeda em Neossolo Litólico húmico. Pesquisa Florestal Brasileira, Colombo, v. 30, n. 61, p. 51-59, 2010.

MALAVOLTA, E.; VITTI, G. C.; OLIVEIRA, S. A. Avaliação do estado nutricional das plantas: princípios e aplicações. 2. ed. Piracicaba, SP: POTAFOS, 1997. 319 p.

MARSCHNER, H. Mineral nutrition of higher plants. 2. ed. London: Academic Press, 2000. 889 p.

MIRANDA, J. R. P.; CARVALHO, J. G.; FREIRE, A. L. O.; FERNANDES, A. R.; SANTOS, D. R.; PAIVA, H. N. Cloreto de sódio e silício e seus efeitos na nutrição mineral e na produção de matéria seca de plantas de moringa. Revista de Ciências Agrárias, Belém, v. 44, p. 81-95, 2005.

MIRANDA, J. R. P.; CARVALHO, J. G.; FREIRE, A. L. O.; FERNANDES, A. R.; SOUTO, J. S.; PAIVA, H. N. Silício e cloreto de sódio e seus efeitos nos teores foliares de macronutrientes, $\mathrm{Na}, \mathrm{Cl}$ e $\mathrm{SiO}_{2}$ em clones de cajueiro anão-precoce (Anacardium occidentale L.). Revista de Ciências Agrárias, Belém, n. 41, p. 203-213, 2004.

MIRANDA, J. R. P.; CARVALHO, J. G.; SANTOS, D. R.; FREIRE, A. L. O.; BERTONI, J. C.; MELO, J. R. M.; CALDAS, A. L. Silício de cloreto de sódio na nutrição mineral e produção de matéria seca de plantas de moringa (Moringa oleifera Lam.). Revista Brasileira de Ciência do Solo, Campinas, v. 26, n. 5, p. 957-965, 2002.

MUNNS, R. Comparative physiology of salt and water stress. Plant, Cell and Environment, v. 25, p. 239-250, 2002.

MUSYIMI, D. M.; NETONDO, G. W.; OUMA, G. Effects of salinity on gas exchange and nutrients uptake in avocados. Journal of Biological Sciences, v. 7, n. 3, p. 496-505, 2007.
NEVES, O. S. C.; CARVAlho, J. G.; ROdRIGUES, C. R. Crescimento e nutrição mineral de mudas de umbuzeiro (Spondias tuberosa Arr. Cam.) submetidas a níveis de salinidade em solução nutritiva. Ciência e Agrotecnologia, Lavras, MG, v. 28, n. 5, p. 997-1006, 2004.

PIZARRO, F. Drenaje agrícola y recuperacion del suelo salino. Madrid: Agrícola Española, 1978. 521 p.

RENGEL, Z. Role of calcium in salt toxicity. Plant, Cell and Environment, Oxford, v. 15, p. 625-632, 1992.

SAUR, E.; LAMBROT, C.; LOUSTAU, D.; ROTIVAL, N.; TRICHET, P. Growth and uptake of mineral elements in response to sodium chloride of three provenances of maritime pine. Journal of Plant Nutrition, New York, v. 18, n. 2, p. 243-256, 1995.

SERRATO VALENTI, G.; FERRO, M.; FERRARO, D.; RIVEROS, F. Anatomical changes in Prosopis tamarugo Phil. seedlings growing at different levels of $\mathrm{NaCl}$ salinity. Annals of Botany, London, v. 68, p. 47-53, 1991.

SHARMA, P.; KUMARI, P.; SRIVASTAVA, M. M.; SRIVASTAVA, $\mathrm{S}$. Removal of cadmium from aqueous system by shelled Moringa oleifera Lam. seed powder. Bioresource Technology, Essex, v. 97, n. 2, p. 299-305, 2006.

VIANA, A. P.; BRUCKNER, C. H.; MARTINEZ, H. E. P.; MARTINEZ Y HUAMAN, C. A.; MOSQUIM, P. R. Teores de Na, $\mathrm{K}, \mathrm{Mg}$ e Ca em porta-enxertos de videira em solução salina. Scientia Agricola, Piracicaba, SP, v. 58, n. 1, p. 187-191, 2001.

VIEIRA, A. M. S.; VIEIRA, M. F.; SILVA, G. F.; ARAÚJO, A. A.; FAGUNDES-KLEN, M. R.; VEIT, M. T.; BERGAMASCO, R. Use of Moringa oleifera seed as a natural adsorbent for wastewater treatment. Water, Air \& Soil Pollution, Dordrecht, v. 206, n. 1-4, p. 273-281, 2010. 
